7.4

itLE: THE FMIT FACILITY CONTROL SYSTEM

ast

AUTHOR(C): R. M. Suyama, D. R. Machen, and J. A. Johnson

SUBMITTED TO: 1981 Particle Accelerator Conference, March 11-13, 1981, Washington, DC

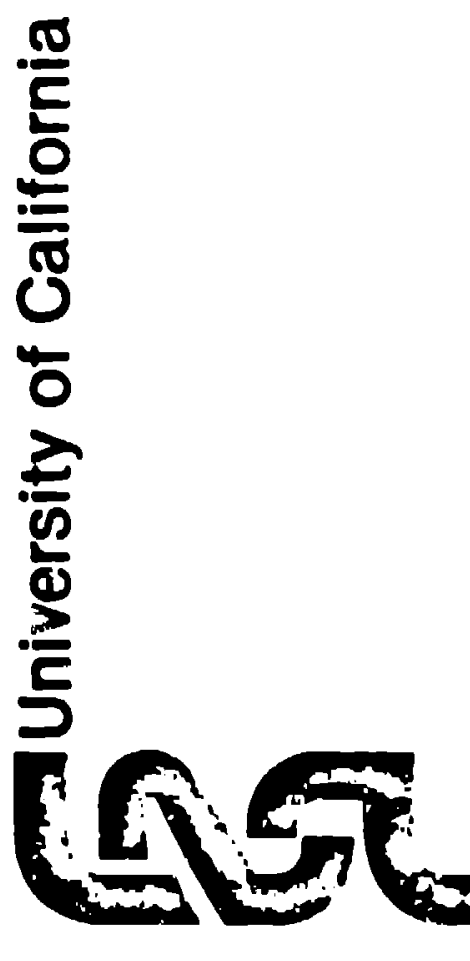

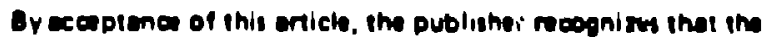

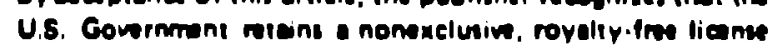
10 publish of reproduce the fublishod lorm of ithic contribu. rion. or 10 allow olmen to do 10 . Tor U.S. Comrnment dur. poses.

The Ler Alemes Belentinc Leborotory nequens that ins pub.

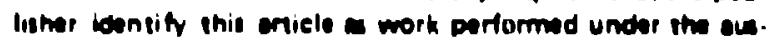
piens al ine U.S. Deporiment of Enarey. 


\section{THE FMIT FACILITY CONTROL SYSTEM ${ }^{*}$}

R. M. Suyama, ** D. R. Machen, and J. A. Johnson

Accelerator Technology Division

Los Alamos National Laboratory, Los Alamos, New Mexico 87545

\section{Surmary}

The control system for the Fusion Materials Irradiation Test (FMIT) Facility, under construction at Richland, Washington, uses current techniques in distributed processing to achieve responsiveness, maintainability and reliability. Developmental experience with the system on the FMI T Prototype Accelerator (FPA) being designed at the Los Alamos Nat ional Laboratory is described as a function of the system's design goals and details. The functional requirements of the FMIT control system dictated the use of a highly operatorresponsive, display-oriented structure, using state-ofthe-art console devices for man-mach ine commur.ications. Further, current technology has allowed the movement of device-dependent tasks into the area traditionally occupied by remote input-output equipment; the system's Jual central process computers communicate with remote communications nodes containing microcomputers that are architecturally similar to the top-level machines. The system thas been designed to take advantage of commercially avallable hardware and software. The use of national and international standards in both hardware and software has minimized the design staff and maximized the flexibility and maintainability of the system.

\section{Introduction}

The FMIT facllity will consist of a 100-mA, continuous-beam, deuteron accelerator and a flowing lithium target that w1ll be used to produce $14-\mathrm{MeV}$ neutrons for materials research, 1.2 and will be directed toward the development of containment materials for use in a controlled thermolluclear fusion reactor. The facility is being bullt at Richland, Washington, and will be operated by the Hanford Eng ineer ing Deve lopment Laboratory (HEDL). The FMIT accelerator design is being performed by the Acceler ator Technology Division of the Los Alamos National Laboratory; a prototype of the front end of the accelerator is under construction at: Los Alamos. The coritrol system for both the FMIT and the FPA will provide the primary data acquisition, control and interface components that integrate ai? the individual systems into a functional facility." The control sistem consists of a distributed computer network, control consoles and remote instrumentation.

\section{Design Goals}

The god of the FMIT Control system is to provide a supervisory control structure through which the facllity operators c, an monitor, tune, operate and shut down the accelerator, lithium target, experimenter and building utility systems from a central control area. The facllity must operate for extended perlod: of time with only minimal operations staff. For this reason, information and cuntrol functions must be presented to the operator in an understandable and usable furmat. Color displays and computer-generated diagrams and graphs are used to solve the machine-toman interface problem. Touch panels and sof tware assignable control knobs are used to solve the man-tomach ine interface problem areas most critical to accelerato. tuning.

\footnotetext{
Work performed under the auspices of the US Department of Energy.

* Hariford Engineering Deve lopment Laboratory employee working at the Los Alamos Nat Ional Laboratory.
}

The overall requirement for the control console, and hence the supervisory control system, was to provide the operator with a "real-time" feel of the systems under control, and to relieve the operator of the tedious rout ine monitoring functions by reporting outof-limits indications or significant parameter changes. Thus, a key design goal of the system was to provide the capability for an operator to request a control detion from the console, to process and transmit the request over the computer network communication link, to perform the action, and to return a response with in a "human response" time frame. A goal of fuur requestresponses per second was established, based upon humanfactors considerations and past experiences at other accelerator facilities. Note that at the same time that an operator requests a control action at the console, the system could be performing numerous other functions such as rout ine surveillance, closed loop control functions, and system logs.

In addition to meeting the technical control requirements, the facflity control sysiem also addresses a limited number of nontechnical design goals. First, because the final system will be operated and maintained by HEDL, but will initially be developed and operated by Los Alamos in support of the FPA, a key to the entire design was to minimize the development of speciailzed hardware and system and communications sof tware. Thus the control system was designed to make the maximum use of existing vendor-supplied-andsupported hardware and sof tware systems. Secondl:., to make the maximum use of the prototype development effort, it was decidad to mike the prototype control system as prototypical as possible; thus, major portions of the prototype applications sof tware will be directly usable on the final factlity by expanding the data base and making only minor' sof tware modifications. This second goal led to the problem of $11 \mathrm{mit}$ ing the larger taclitity equipment procurements to the same. successful prototype equipment vendor. Th is problem was solved by combining the FMIT facllity and $F P A$ specifications for all major procurements and by adopting the international CAMAC standard for the process input and output system. Thus, we were assured that the successful vendors had the requisite capabilities to satisfy both FMIT and FPA requirements, and that mulitiple vendor; were avallable to supply equipment consistent with the CAMAC standards.

\section{Design Detalls}

In accordance with our design goals, Oigital Equipment Corporation's POP-1I and $L S I-1 \mid$ ilne of equipment was selecteo by a competitive bidding process as having the necessary range of central processors operating under the same basic sof tware operat ing system (RSX-11), and the associated hardware ald software to sat isfy our system requirement's. Dual POP-11/70s were bid for the FMIT central computer sys. tem with the capabllity to upgrade to VAXs if addit tonal processing power is needed. Dual POP-11/60s were procured as having the necessary power to meet the FPA central computer system requirements. Figure I shows the FPA control room and the two PDP-11/60 computers with their assoclated peripheral equipment.

The dual central computers are linked to each other, and to six (four for the FFA) LSI-11-based instrumentation Subsystems, by intelligent communications controllers known as DMC-lls. These controllers 


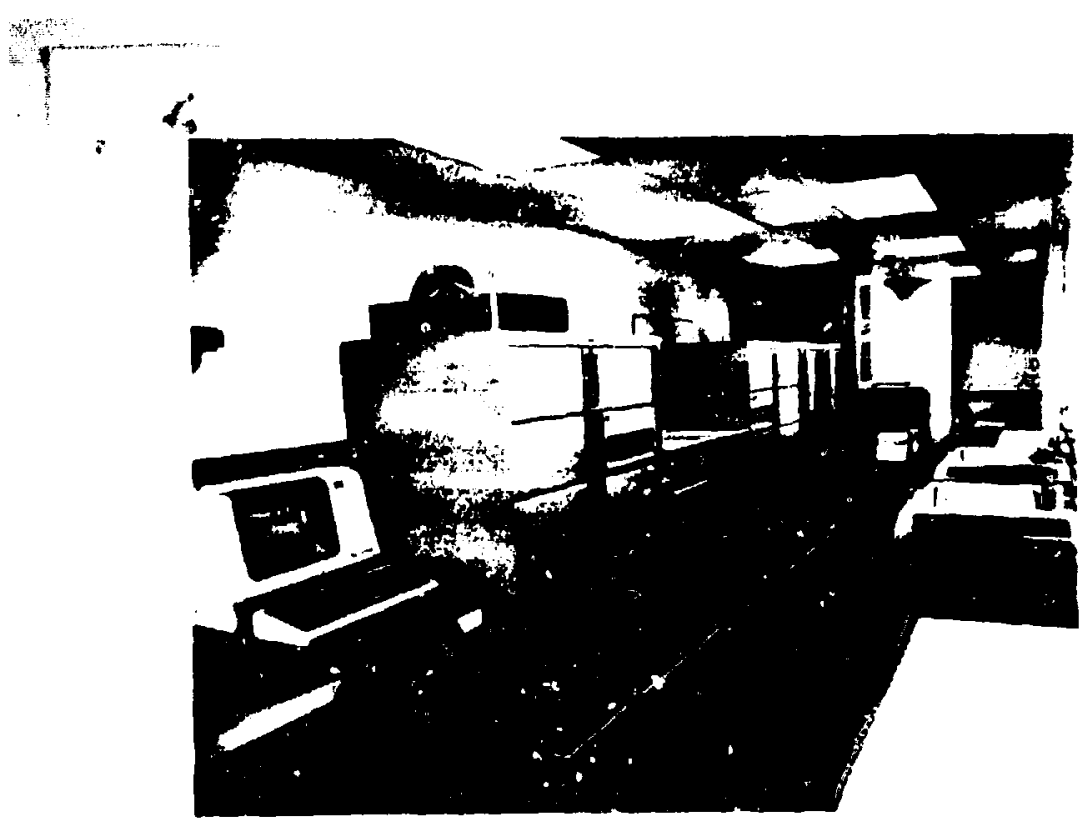

Fig. 1. FPA Control Reom.

are a Unibus*-based device and are compatible with the central computers; to interface the $O M C-11$ and the associated computer network into the local Instrumentation Subsystem's LSI-11/23 microcomputer, a short section of Unibus and a Unibus-to-Q-bus* converter are necessary. The LSI-11/23 microcomputer is used as the Instrumentation Subsystem processor, which is physically located in a CAMAC Auxilliary Crate Controller (ACC) module. The use of LSI-11/23-based ACCS al lows applications code to be developed, using the resources of the central computers and then downloaded through a fiber optic, bit-serial communications link for execution. The ACC allows the LSI-11; 3 to access and control its own CAMAC dataway, as we 11 as additional crates (by way of the CAMAC Serial Highway). In an extremely efficlent manner. It will be possible to place additional processing capability in any CAMAC crate in an Instrumentation Subsystem. CAMAC interface modu?es are then wired to the various FMIT subsystems through a conventional r.able plant and, where necessary, isolation instrumeiltation modules. Interlock and switching logical control for several FMIT subiystems is being provided by a Gould Programable Controller. A block Oiagram of the FMIT control system is shown in Fig. 2 , and $F$ ig. 3 shows the instrumentation Subsystem As sembiy in the FPA injector crintrol area.

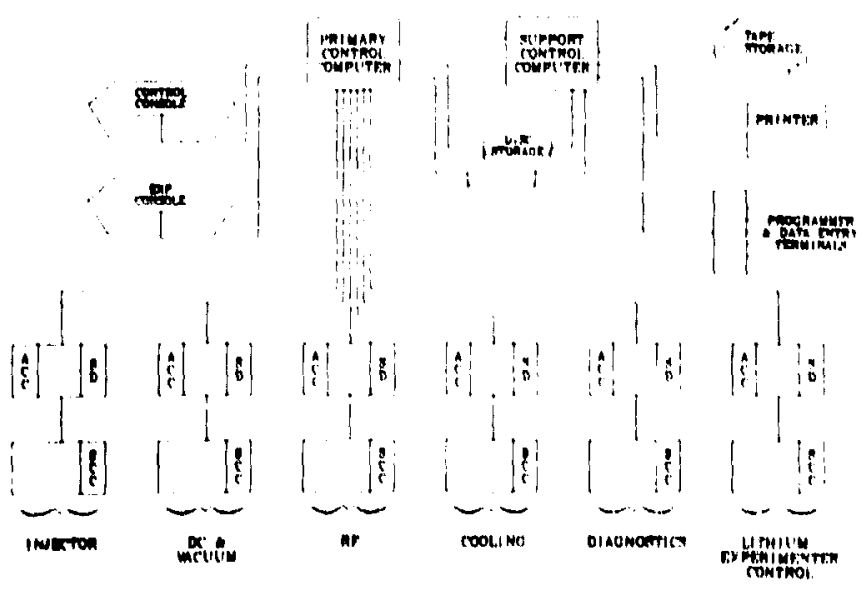

Fig. 2. Bluck diagram of the FMIT Control System.

DoTgital Equpment Corporation bus structure

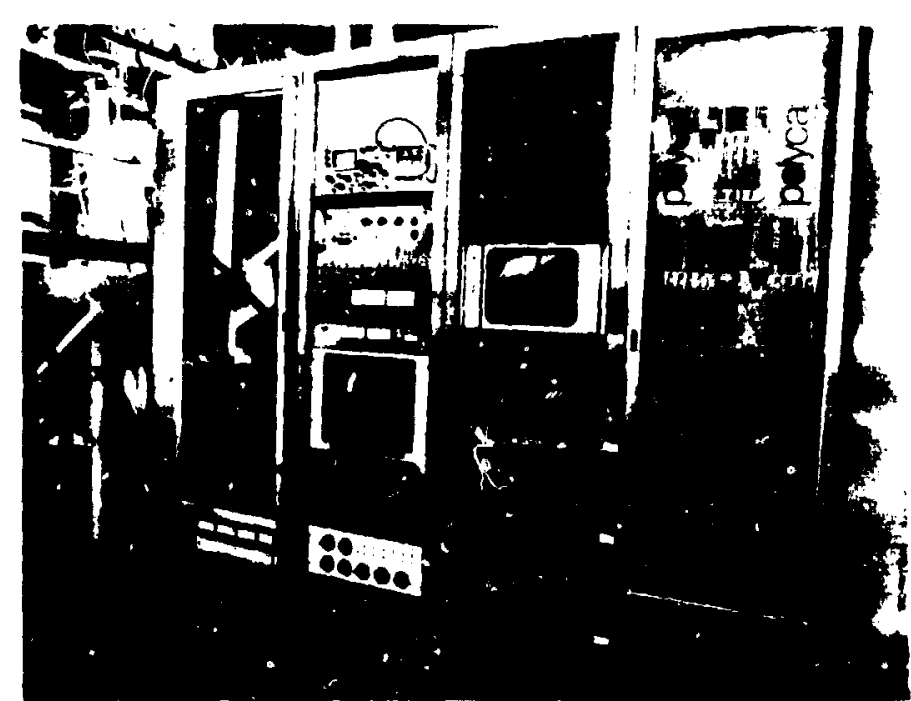

Fig. 3. FPA injection instrumentation subsystem.

The consoles for the FMIT and the FPA have been designed around graphic display devices and touchsensitive panels for each display device. The FPA console is shown in $\mathrm{Fig.} \mathrm{4}$, indicating the positioning of the various elements. The raster scan colorgraphic device (AED-512) is interfaced to the computer with a DMA channel so that display changing and updating take place in an acceptable time frame.

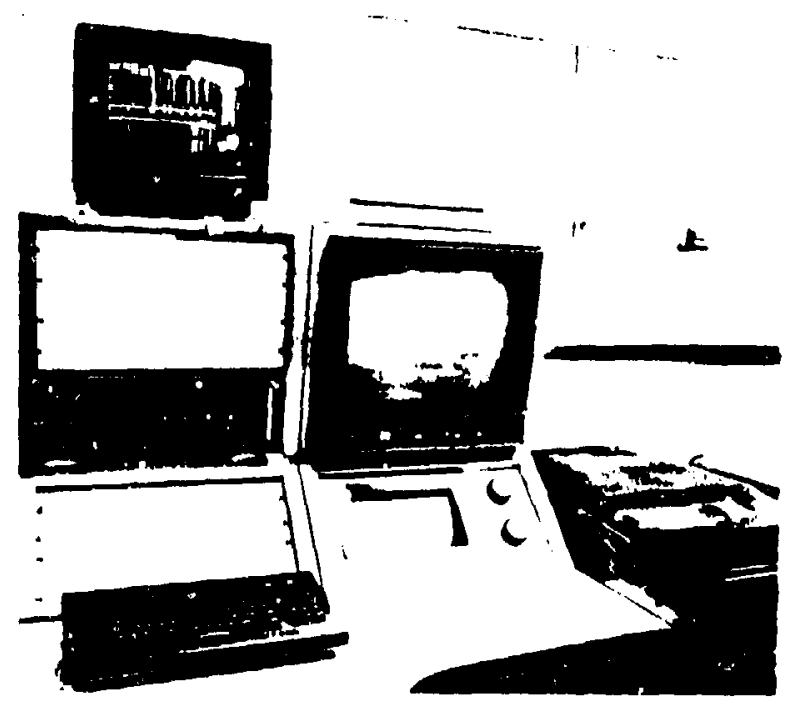

Fig. 4. FPA control console.

This device has an Elographics, Inc., touch panel for man-machine communtcations. Below the color display, - large alpha-numeric $(23 \mathrm{c:m} \times 30 \mathrm{~cm})$ discharge pane? with touch panel (Vue-Polnt, General Digftal Corp.) is positiuned, together with two software-assignable incremental shaft-encoder knobs. Overall process selection takes place on the color display, whereas the mcre detalled data feedback and contrul are accomplished on the knob and display panel. The center section of the console is reserved for analog communications and tiagnostics.

\section{Network Communications}

in 0ctober 1980, network communtcations evaluation was completed using the console, main computer system, and two prototype Instrumentation Subsystems. The results of this eyaluation are reported below. 
Network communications between the FPA criltral computers and the Instrumentation Subsystems ire accomplished through the vendor-supplied and supported DECNET communications network software. Performance tests of DECNET, operating in the environment of the FPA control system, have measured the $t$ ime required for a 256-byte message to be sent from a user task in the POP-11/60 control computer to a user task in either the support PDP-11/60 or to an LSI-11/23 in an Instrumentation Subsystem, and back again over the communications network. Table 1 summarizes these performance test results for both DECNET and DLX; OLX is a sutset of DECNET that provides only the line handler features. In addition, timing tests for round-trip messages between a POP-11/60 and an LSI-11/23 were made at different line speeds and message sizes. These results are shown in Table 2 .

TABLE 1

MESSAGE TIMES FOR ROUND TRIP SFND AND RECEIVE FOR A 256 -BYTE MESSAGE

$\begin{array}{ccc}\text { DECNET } & \begin{array}{c}\text { PDP-11/60 to PDP-11/60 } \\ (1 \text { Megabit/s link) }\end{array} & \begin{array}{c}\text { PDP-11/60 to LSI-11/23 } \\ \text { (56 Kilobit/s link) }\end{array} \\ & 45 \mathrm{~ms} & 155 \mathrm{~ms} \\ 17 \mathrm{mis} & 94 \mathrm{~ms}\end{array}$

TABLE 2

DECNET ROUNO TRIP TRANSFER RATES

Messar

\begin{tabular}{|c|c|c|c|}
\hline Bytes & $60 / 60(1 \mathrm{MB} / \mathrm{s})$ & $60 / 60(56 \mathrm{kB} / \mathrm{s})$ & $60 / \mathrm{LSI} / 56 \mathrm{~KB} / \mathrm{s}$ \\
\hline 40 & $39 \mathrm{~ms}$ & $91 \mathrm{~ms}$ & $91 \mathrm{~ms}$ \\
\hline 256 & $45 \mathrm{~ms}$ & - & $156 \mathrm{~ms}$ \\
\hline
\end{tabular}

$1000 \quad 71 \mathrm{~ms} \quad 415 \mathrm{~ms} \quad 418 \mathrm{~ms}$

These timing results indicate tiat using a communications concept of one control message correspon ing to one DECNET message would not be fast enough to satisfy the data communications requirements of either the FPA or the FMIT facilities. A packing technique was used to derandomize the message flow and to help increase the overall message transfer rate. This technique used message handler at each end of the link to accumulate a number of short control messages into a DECNET message, which in turn was sent at a $f$ ixed rate. Thus, several control messages are sent in each DECNET message.
Several tasks were written to demonstrate the various control features needed on accelerator control systems. These include the periodic logging of a set of data channels, the display of data channels on the display CRT, the software connection of corltrol knobs to command channels, and the plotting of the results of calculations based upon data acquired by the system. The results of these tests are subjective at best, but displays of channels connected to comand channels can be updated at least 5 times per second. Data arrays of 100 points for plotting can be read, transported over the network, and plotted in 2 to 3 seconds. These $t$ imes are obtained while other tasks are running and requesting data.

Tasks were written to load the PDP-11/60 control computer and to load the data communications network. A noticeable degradation in performance occurred only after the control computer was loaded to $75 \%$ of capacity or greater. The effect of message loading could not be noticed until the number of additionai messages caused the 256-byte message packet to over-

flow. Two packets would then be sent when originally one had been sufficient.

\section{Conclusions}

At the time of this writing, the control room, main computers and console for the FPA have been installed and made operational. Instrumentation Subsj'stems for the injector, beam diagnostics and the prototype accelerator cooling system are in various stages of installation and checkout.

Installation and cormissioning of the FPA control system will cont inue for the next year. The results of this effort will be directly apolicable to the FMIT control system.

\section{Acknowledgmerits}

The authors would like to acknowledge the joint Hanford Engineering Development Laboratory/Los Alamos National Laboratory controls staff for their efforts in the design and and development of the FMIT and FPA Facility Control Systems.

\section{References}

1. R. A. Jameson, "High Intensit: Deuteron Accelerator (FMIT)," IEEE Trans.on NUCl. SCi., NS-26 (3), pp. 2985-2991 (June 1979).

2. E. L. Kemp, D. D. Armstrong, J. O. Hartsell, D. J. Liska, and E. F. Parker. "Stacus Report on the Fusion Materials Irradiation Test +acility," this conference.

3. J. A. Johnson, D. R. Machen, and R. M. Suyama, "Distributed Control Systen for the FMlT." Proc. 1979 Linear Accelerator Conf., Sent. 11-i3, 1979 Montauk, New York (Brookhaven Na., Lab., Uptorl NY) BNL. -51134, p. 279 